Review

\title{
Circadian rhythms and attention deficit hyperactivity disorder: The what, the when and the why
}

\author{
Andrew N. Coogan ${ }^{a, *}$, Alison L. Baird ${ }^{b}$, Aurel Popa-Wagner ${ }^{c}$, Johannes Thome ${ }^{c}$ \\ a Maynooth University Department of Psychology, National University of Ireland, Maynooth, Ireland \\ ${ }^{\mathrm{b}}$ Department of Psychiatry, University of Oxford, Oxford, UK \\ c Department of Psychiatry, School of Medicine, University of Rostock, Germany
}

\section{A R T I C L E I N F O}

\section{Article history:}

Received 30 October 2015

Received in revised form 11 January 2016

Accepted 13 January 2016

Available online 15 January 2016

\section{Keywords:}

ADHD

Circadian

Sleep

\begin{abstract}
A B S T R A C T
Attention deficit hyperactivity disorder (ADHD) is a common neurodevelopmental condition characterised by impulsivity, inattention and hyperactivity. Aside from these core psychopathologies, sleep disturbances are found to be highly comorbid with ADHD, and indeed dysregulated sleep may contribute to some of the symptoms of the disorder. It is not clear how sleep disturbances come to be so common in ADHD, but one putative mechanism is through the circadian timekeeping system. This system underpins the generation of near 24-hour rhythms in a host of physiological, behavioural and psychological parameters, and is a key determinant of the sleep/wake cycle. In this paper we review the evidence for sleep and circadian rhythm disturbance in ADHD, examine the possible mechanistic links between these factors and the disorder and discuss future directions through which the circadian clock can be targetted for ADHD symptom relief.
\end{abstract}

(c) 2016 Elsevier Inc. All rights reserved.

\section{Contents}

1.1. Introduction ... . . . . . . . . . . . . . . . . . . . . . . . . . . . . . . . . . . . . . . 74

1.2. The circadian system and clock genes . . . . . . . . . . . . . . . . . . . . . . . . . . . . . . . . . . . . . . . . . . . . . . . . . . . . . 75

1.3. ADHD and sleep . . . . . . . . . . . . . . . . . . . . . . . . . . . . . . . . . . . . . . . . . . . 75

1.4. Circadian dysfunction in ADHD . . . . . . . . . . . . . . . . . . . . . . . . . . . . . . . . . . . . . . . . . . . 76

1.5. Mechanisms linking the circadian system to ADHD . . . . . . . . . . . . . . . . . . . . . . . . . . . . . . . . . . . . . 77

1.6. Conclusion and agenda for future research . . . . . . . . . . . . . . . . . . . . . . . . . . . . . . . . . . . . . . 79

References . . . . . . . . . . . . . . . . . . . . . . . . . . . . . . . . . . . . . . 79

\subsection{Introduction}

Circadian rhythms are recurring patterns in a host of physiological, behavioural and psychological domains that repeat on a near 24-hour basis. Disturbances in circadian rhythms are implicated in a large number of significant and common medical conditions (Smolensky et al., 2015). Circadian rhythm abnormalities are associated with key and

Abbreviations: ADHD, attention deficit hyperactivity disorder; DSPS, delayed sleep phase syndrome; HPA, hypothalamic-pituitary-adrenal axis; SCN, suprachiasmatic nucleus; SHR, spontaneously hypertensive rat; WKY, Wistar Kyoto rat.

* Corresponding author at: Department of Psychology, Maynooth University, National University of Ireland, Maynooth, County Kildare, Ireland.

E-mail address: andrew.coogan@nuim.ie (A.N. Coogan). common psychiatric conditions, including major depression, schizophrenia and bipolar disorder (Lall et al., 2012; Pritchet et al., 2012). Further, sleep is significantly disturbed in such conditions: prevalence rates of DSM-defined insomnia in major depression is found to be $41 \%$ (Stewart et al., 2006), and sleep disturbance/dysfunction is present in $90 \%$ of patients with major depression (Breslau et al., 1996). Disturbance of the circadian clock may be a key factor in explaining the high level of sleep disturbances co-morbid with common psychiatric conditions. As such, the circadian systems may be a therapeutic target for psychiatric and psychological disorders, as well as for psychiatric and psychological co-morbidities of common physical diseases (Buttgereit et al., 2015). As circadian abnormalities are implicated in attention deficit hyperactivity disorder (ADHD; Kooij and Bijlenga, 2013), and sleep disturbances in ADHD are also common (Schredl et al., 2007), we will explore the mechanisms through which circadian abnormalities may 
come to be co-morbid with ADHD and examine their potential therapeutic consequences.

\subsection{The circadian system and clock genes}

The circadian system underpins the generation and maintenance of self-sustained, 24-hour oscillations in physiological and behavioural processes that are linked to, and amendable by, internal and environmental changes. Circadian rhythms are sustained at the molecular level by a series of interconnected transcription-translation feedback loops that control the expression of clock genes (CLOCK, BMAL, PER, CRY, REV-ERB alpha and RORA) comprising the molecular circadian clock (Dibner et al., 2010). The circadian expression of these genes is regulated through E-boxes, REV-ERB alpha/ROR (retinoic acid-related orphan receptor) response elements (RRE), and DBP/E4BP4 binding elements (Albrecht, 2012). During the clock gene cycle, CLOCK and BMAL dimerise and bind to the promoter region of period and cryptochrome genes to induce their expression. Subsequently, PER and CRY form a repressor complex and relocate to the nucleus where they inhibit the genes induced by the CLOCK/BMAL protein complex, including their own transcription and forming a negative feedback loop. The REVERB/ROR component of the cycle provides another feedback arm unto BMAL1 transcriptional activity (Albrecht, 2012). There is considerable post-translational modification of clock gene protein products, which alters protein stability and turn-over and fine-tunes the period of the cycle (Meng et al., 2008). Output of the clock is generated by the global regulation of transcriptional architecture by clock genes (Koike et al., 2012 ) and a recent analysis revealed that $43 \%$ of protein coding genes show circadian rhythms in their expression in at least one mammalian tissue (Zhang et al., 2014).

From a neurobiological perspective, in mammals the master circadian pacemaker resides in the suprachiasmatic nuclei $(\mathrm{SCN})$ of the anterior hypothalamus and the $\mathrm{SCN}$ is primarily responsible for the generation of circadian rhythms (Dibner et al., 2010). The SCN is entrained to the external 24-hour day by receiving light information from the retina via a specialised neural tract, termed the retinohypothalamic tract (RHT; Hughes et al., 2015), although the presence of extra SCN oscillators have also been demonstrated (Guilding and Piggins, 2007; Dibner et al., 2010). The role of the SCN as the master pacemaker is confirmed by evidence that SCN lesions abolish most physiological, endocrine and behavioural rhythms, and SCN transplants can restore rhythmicity in previously arrhythmic, SCN-lesioned rodents (Guilding and Piggins, 2007). The SCN consists of two paired nuclei, each nucleus containing $\sim 10,000$ neurons, and it is situated bilaterally to the third ventricle and immediately dorsal to the optic chiasm (Abrahamson and Moore, 2001). The positioning of the SCN is therefore optimal for receiving visual input for entrainment to the light-dark cycle via the RHT. The non-visual photoreceptive system through which light primarily acts on the SCN is via the novel melanopsin system, in which a small proportion of retinal ganglion cells express this photopigment and are intrinsically photosensitive (Hughes et al., 2015). The axons of these ganglion cells make up the RHT and transmit photic information to the SCN via a mono-synaptic glutamatergic projection that also involves the neuropeptide PACAP (Hughes et al., 2015). Circadian patterns in neuronal firing is a key feature of the SCN, and blockage of SCN neuronal activity results in behavioural arhythmicity, with rhythmicity restored when SCN neuronal activity is restored (Schwartz et al., 1987). The electrical firing rate exhibits a rhythm with a period of $\sim 24 \mathrm{~h}$ in the SCN, with a higher frequency during the day and lower frequency during the night (McArthur et al., 2000). The clock gene cycle is linked to the day/night variations in the SCN neuronal firing, providing a link between the molecular clockworks and the SCN's neurophysiological output (Belle et al., 2009; Jones et al., 2015).

An important feature of the circadian system are rhythmic output signals from the $\mathrm{SCN}$, and other areas that are driven by the $\mathrm{SCN}$, which are responsible for entrainment of peripheral oscillators (Dibner et al.,
2010). The adrenal glucocorticoid stress hormone cortisol plays a key role in the hypothalamic-pituitary-adrenal (HPA) axis, but is also an important output of the master circadian pacemaker, and its secretion is regulated by output pathways of the SCN involving arginine vasopressin and corticotropin-releasing hormone (Keller et al., 2006). Cortisol displays a circadian rhythm in its secretion consisting of an increase just before waking up in the morning, a peak within an hour of waking and then a decline over the rest of the 24-hour day, and environmental light exposure directly after awakening increases the amplitude of the morning peak (Van Someren and Riemersma-Van Der Lek, 2007). Cortisol is thought to be involved in the regulation of circadian rhythms in particular the entrainment of the peripheral oscillators (Keller et al., 2006; Van Someren and Riemersma-Van Der Lek, 2007).

Another important output of the circadian system is the pineal hormone melatonin, which is synthesised in the pinealocytes from the precursor tryptophan. The secretion of melatonin exhibits a clear circadian rhythm, with peak plasma levels usually between 02:00 and 03:00 am and sympathetic input from the cervical ganglion under influence from the SCN via GABAergic mechanisms is thought to regulate pineal melatonin synthesis (Arendt, 2005a). Furthermore input from the master pacemaker is essential for the synchronisation of the circadian rhythm of melatonin to the light-dark cycle and the persistence of the rhythm (Arendt, 2005b). Melatonin also plays a role in mediating various circadian activities throughout the body including the regulation of reproductive capacity, hormone secretion, immune responsiveness, daily rhythms of activity and entrainment of sleep/wake cycles. The circadian rhythm of melatonin synthesis is closely linked to the sleep rhythm as demonstrated by the nocturnal onset of melatonin secretion, which usually occurs $2 \mathrm{~h}$ in advance of the individual's habitual bedtime, and correlates with evening sleepiness and the sleep promoting effect of exogenous melatonin (Arendt, 2005b). Melatonin is believed to have a strong entraining influence on the master circadian clock through its ability to directly feed back to the SCN (Pevet and Challet, 2011). Indeed, melatoninergic agonists can be used to entrain rhythms for the treatment of non 24-hour sleep-wake disorder in blind subjects (Neubauer, 2015).

With regard to the role of the circadian system in regulating sleep/ wake behaviour, the classic two process model proposed by Borbély (1982) suggests that there are intertwined homeostatic and circadian inputs to determining sleep/wake states. The homeostatic process signals time spent awake, and the circadian process signals the rhythmic drive towards wakefulness; at any given time the drive towards sleep is dependent on both the homeostatic pressure and the circadian phase. The interaction between the sleep homeostatic and circadian systems appears to be intricate, with alterations in clock genes leading to changes in sleep homeostatic processes (Franken, 2013; Freyburger et al., 2015). Further, the SCN may have a role in determining sleep architecture (Lee et al., 2009); conversely sleep deprivation alters the phase of the circadian clock (Antle and Mistlberger, 2000) and alters SCN neuronal activity (Deboer et al., 2007). These findings indicate the very intimate relationship between the homeostatic and sleep processes. As such, circadian processes are implicated in sleep disorders aside from those considered circadian rhythm sleep disorders. For example, phase changes have been found to be associated with insomnia (Lack et al., 2008). Therefore, circadian abnormalities observed in chronic conditions may contribute to co-morbid sleep disturbances and disorders. In this context, we will now explore the evidence for association of ADHD with both sleep disturbance and circadian dysfunction.

\subsection{ADHD and sleep}

$\mathrm{ADHD}$ is a heterogeneous condition that is one of the most frequent disorders in child and adolescent psychiatry, with a prevalence of approximately 7\% (Thomas et al., 2015). Symptoms associated with ADHD in children include attentional difficulties, motor hyperactivity, impulsivity and sleep disturbance. ADHD continues from childhood in 
approximately $50 \%$ of patients who go on to express an adult form of the condition (Biederman and Faraone, 2005). Similar to the situation in children, ADHD in adults manifests itself through behavioural and attentional problems and ADHD is associated with lower educational and work standards, delinquency and anti-social behaviour (Rösler et al., 2004). There are various aetiological hypotheses propounded for ADHD. Idiopathic frontal lobe dysfunction is strongly implicated in the pathophysiology of ADHD, with other brain regions affected in ADHD including the cerebellum, cingulate cortex and basal ganglia (Schneider et al., 2006). Altered dopaminergic and other monoaminergic neurotransmission is believed to play a significant role in ADHD and this is the basis for the therapeutic use of psychostimulants in the management of ADHD (Biederman and Faraone, 2005). Genetic studies of ADHD have implicated various components of the dopaminergic system as well as other candidate genes (synaptic vesicle proteins, serotoninergic components, growth factors), and gene-environment interactions are believed to be significant in the complex aetiology of ADHD (Hawi et al., 2015).

One important issue in ADHD is the extent to which associated sleep problems contribute to the psychopathology of ADHD, and the nature of the link between sleep mechanisms and the pathophysiology of ADHD. Prevalence of insomnia in adult ADHD is estimated at 27\% (Schredl et al., 2007) and sleep disturbances may occur in up to $83 \%$ of adult patients (Sobanski et al., 2008). ADHD is associated not only with nonspecifically disrupted sleep, but also with parasomnias, hypersomnias and limb movement disorders (Walters et al., 2008). Mahajan et al. (2010) have reported a significant correlation between hyperactiveimpulsive symptoms and sleep quality in non-medicated adults with ADHD. People with delayed sleep phase disorder, a circadian rhythm sleep disorder, show significantly more frequent ADHD symptoms than control populations (Sivertsen et al., 2015). Further, a role for sleep disturbance in the pathophysiology of ADHD is indicated by findings that some of the core symptoms of ADHD (inattention, impulsiveness and restlessness) are by-products of sleep deprivation (Corkum et al., 1998; Wulff et al., 2010), and sleep deprivation has been shown to cause behavioural and cognitive problems (Babkoff et al., 1991). The inattentive and hyperactive symptoms of ADHD have been associated with children who suffer from obstructive sleep apnoea and habitual snoring (Chervin, 2005; Chervin et al., 2005; Lim et al., 2008). Parental and self reports of sleep in childhood ADHD have indicated a number of sleep deficits including reduced sleep duration (Lim et al., 2008), an increase in the degree of snoring (O'Brien et al., 2003a) and increased likelihood of suffering from nightmares (Chiang et al., 2010). Sex differences in sleep reports has been indicated, with female ADHD patients reporting more difficulties sleeping; however the authors speculate that this finding could be due to parental expectations of girls finding it easier to sleep than boys (Lim et al., 2008). Analysis of sleep quality in ADHD-subtypes (inattentive, hyperactive-impulsive or combined) has revealed that combined and hyperactive-impulsive subtypes were reported to exhibit increased sleep duration in comparison to the inattentive subtype and healthy controls, whereas daytime sleepiness and napping, early insomnia, middle insomnia, sleep terrors and snoring was increased in the combined and inattentive subtypes in comparison to the hyperactive-impulsive subtype (Chiang et al., 2010). Furthermore, circadian rhythm disturbance, sleep-talking, nightmares and nightmare disorders, and circadian rhythm sleep disorders were more predominant in the combined subtype than the inattentive subtype of childhood ADHD (Chiang et al., 2010). In a recent large populationbased study, ADHD symptoms in a non-clinical sample of adolescents were found to be associated with a range of sleep disturbances (eg. less sleep efficiency, later bedtime, longer sleep latency, longer waking after sleep onset, higher subjective sleep need), and that there was a linear relationship between all sleep variables and ADHD symptom scores (Hysing et al., 2015).

Actigraphy and polysomnography have also been utilised as methods of measuring the sleep/wake cycle and sleep and activity parameters (Littner et al., 2003). Actigraphic analysis has shown daytime activity of children with ADHD in a clinical setting to be greater than controls (Dane et al., 2000). In conjunction with sleep diaries, actigraphy has demonstrated increased variance in a number of sleep measures in childhood ADHD, including sleep onset time, sleep duration and true sleep time, thus indicating greater sleep instability in childhood ADHD (Gruber et al., 2000). In adult ADHD, actigraphy has revealed greater daytime activity than in the control population, although there are differing reports regarding increases in nocturnal activity (Boonstra et al., 2007; Baird et al., 2012). Actigraphy has also been used to describe decreases in sleep efficiency, lengthening of sleep onset latency and shorter bouts of uninterrupted sleep in ADHD in adults with or without comorbid sleep onset insomnia (Boonstra et al., 2007, Van Veen et al., 2010). Polysomnographic studies have revealed reduced sleep efficiency, and increased awakenings and percentage wakefulness after sleep onset and reduced sleep efficiency in ADHD (Dagan et al., 1997, Sobanski et al., 2008; Picchietti et al., 1998, O'Brien et al., 2003a). The percentage of rapid-eye movement (REM) sleep has also been shown to be reduced in ADHD (O'Brien et al., 2003a,b; Sobanski et al., 2008), and this could have implications for behavioural functioning, since REM sleep is associated with learning and performance, including attention, memory and language (Diekelmann and Born, 2010).

\subsection{Circadian dysfunction in ADHD}

As the circadian clock is central to the regulation of the sleep-wake cycle as previously described, studies have aimed to establish if circadian deficits are evident in ADHD. One factor in which inter-individual differences in circadian function can be examined is diurnal preference and/or chronotype. Adult ADHD is associated with evening preference; Baird et al. (2012) report later diurnal preference in adult ADHD, a finding that is also reported by Voinescu et al. (2012) in participants with likely-adult ADHD via the ARSR screening instrument. Rybak et al. (2007) report that greater than $40 \%$ of adults with ADHD display evening preference, whereas only $18.5 \%$ exhibited morning preference. These findings contrast to the age-matched general population wherein only $10.8 \%$ exhibit evening preference and $40.2 \%$ exhibit morning preference (Rybak et al., 2007). Greater eveningness correlates with inattention and increased impulsivity; sleep deficiency may play a role in these effects as eveningness is associated with shortened sleep (Rybak et al., 2007). In the general population, eveningness is associated with altered emotionality and ADHD-related traits such as apathetic, volatile and disinhibited temperaments are associated with evening orientation (Ottoni et al., 2012), as is sensation-seeking behaviour (Kang et al., 2015). Circadian disturbance is further implicated in ADHD by findings that seasonal affective disorder, a form of depression intimately linked to circadian dysfunction (Lewy et al., 2006), is found to be significantly comorbid with ADHD (Levitan et al., 1999, Amons et al., 2006, Van Veen et al., 2010; Bijlenga et al., 2013a).

As previously described, melatonin is a key output and regulator of the circadian clock, and plays an important role in the modulation of the sleep-wake cycle. A reduced amplitude of the melatonin rhythm in adult ADHD has been shown (Baird et al., 2012), although it is thought that this may be in part due to light suppression of melatonin during periods of increased nocturnal activity, which in turn may further exacerbate the sleep disruption present in these individuals. A perhaps better validated perturbation to the melatonin rhythm documented in ADHD is a delay in dim light melatonin onset (a key marker of internal circadian phase), and also sleep and wake time (as measured by actigraphy), which have been associated with both childhood and adult ADHD when comorbid with sleep onset insomnia, whereas both child and adult ADHD patients, who did not suffer from the sleep disorder, displayed normal dim light melatonin onset timing (Van der Heijden et al., 2005, Van Veen et al., 2010). This delay in circadian timing of the sleep/wake cycle observed in sleep onset insomnia is 
characteristic of delayed sleep phase syndrome (DSPS), and therefore it has been proposed that sleep onset insomnia is a circadian rhythm disorder that is comorbid with ADHD (Van der Heijden et al., 2005, Van Veen et al., 2010). Furthermore, subtype differences in the prevalence of sleep onset insomnia have been indicated, with a decreased number of the inattentive ADHD subtype of adults displaying symptoms of sleep onset insomnia in comparison to the other subtypes (Van Veen et al., 2010). Inattentive subtype patients, not suffering from sleep onset insomnia, exhibited longer sleep duration and more stable sleep/wake rhythms in comparison to those with sleep onset insomnia (Van Veen et al., 2010). This is in accordance with previous reports that inattentive subtypes of ADHD are sleepier during the day and sleep for longer durations at a time, and dysregulation of the melatonin rhythm may play a role in mediating these associations (Gau et al., 2007, Van Veen et al., 2010). Reports of delayed timing of sleep onset are not ubiquitous, as Fargason et al. (2013a) report that subclinical sleep disturbances in adults with ADHD are not associated with alterations in sleep-timing. Therefore, the presence or absence of both insomnia and sleep timing alterations may be used in the future to define sub-groups of adults with ADHD. Age may also be an important factor in assessing functional circadian abnormalities in ADHD, as Nováková et al. (2011) report that in children with ADHD there are not changes in the melatonin profile compared to controls; however when split into age-groups, the data reveals that older children with ADHD do display changes in the melatonin profile, but that younger children do not.

It has been proposed that dysfunction of the behavioural inhibition system could be responsible for some of the altered behaviours characteristic of ADHD (Lackschewitz et al., 2008). It has also been postulated that if a dysfunctional behaviour inhibition system is a causative factor of ADHD, then an abnormal hypothalamic-pituitary-adrenal (HPA) axis response to stress should be observed in ADHD (Hong et al., 2003). Lower circulating cortisol levels in response to stress has been associated with many of the characteristics of childhood ADHD, including maladaptive behaviour (Hastings et al., 2009) and poorer cognitive performance (Hong et al., 2003), as well as being associated with a decreased degree of anxiousness in childhood ADHD (Hastings et al., 2009). These findings have been replicated in a study of adult ADHD, which found that lower cortisol levels in response to stress were associated with ADHD (Lackschewitz et al., 2008). Under-reactivity of the HPA-axis in response to stress has been associated with the hyperactive/impulsive subtype of ADHD (Virkkunen, 1985, Moss et al., 1995, Hong et al., 2003, Blomqvist et al., 2007). However, the inattentive ADHD subtype has also been shown to display blunted cortisol levels and hence impaired HPA-axis functioning in response to stress (Randazzo et al., 2008). Other studies have shown that low-cortisol responsivity to psychosocial stress is associated with childhood ADHD-combined type, but not for those with ADHD-inattentive type (van West et al., 2009). Possible reasons for these discrepancies could be the effects of treatment, comorbidity and study design. Sex differences in the stress response have been identified in childhood ADHD, with elevated early morning cortisol levels in boys, and decreased levels in girls (Sondeijker et al., 2007).

Circadian factors may be important in such processes as the HPA axis is known to be under strong circadian control (Nicolaides et al., 2014). Studies of the circadian rhythm of cortisol secretion in ADHD indicate a significant phase-delay of the cortisol rhythm relative to wakening time in adult ADHD (Baird et al., 2012), but no changes in the diurnal profile of cortisol under post-stress conditions (Hirvikoski et al., 2009). Abnormal cortisol rhythms have been associated with the hyperactive component of childhood ADHD (Kaneko et al., 1993; Blomqvist et al., 2007). The cortisol awakening response has also been studied in children suffering from ADHD with comorbid disruptive behaviour disorder, and it has been shown that whilst childhood ADHD patients exhibit a normal cortisol awakening response, those ADHD patients with comorbid oppositional defiant disorder exhibit a dampened cortisol awakening response (Freitag et al., 2009).
Further functional studies of circadian rhythms in ADHD have also provided evidence for circadian dysfunction associated with the disorder. Delays in melatonin secretion and desynchrony between melatonin secretion and sleep onset have been described in adult ADHD, as well as delayed activity and body temperature rhythms (Bijlenga et al., 2013b). These findings highlight the importance of assessing multiple phasemarkers in ADHD in order to understand the significance and interrelationships between phase-alterations and desynchronisation of different pacemakers and circadian outputs. Gamble et al. (2013) provide further evidence for delayed rhythmicity by demonstrating delayed sleep onset timing assessed by actigraphy in adult ADHD. Adult ADHD is associated with loss of rhythmicity in clock gene (PER2 and BMAL1) expression in a peripheral oscillator, the oral mucosa (Baird et al., 2012). Given that the nature of the oscillator in the oral mucosa is very incompletely understood, such alterations may be a proxy for more central clock dysfunction, or may be consequences of more local events such as altered feeding patterns in ADHD. There have been reports of remarkable circadian abnormalities associated with ADHD; Fargason et al. (2013b) published a case-report of complete reversal of the sleep/wake cycle in an adult man with ADHD, whilst Coogan et al. (2015) present actigraphy from an adult with ADHD who displays a bimodal sleep/wake cycle. However, notwithstanding these cases it is worth noting that actigraphy shows significantly less fragmented rhythms in ADHD than the highly disorganised rhythms, which are reported in schizophrenia for example (Wulff et al., 2010).

Chronotherapeutic approaches that may address underlying phasedelays or counter circadian desynchrony, have been trialled in ADHD and been shown to have some promise to date. Rybak et al. (2006) report that light therapy is associated with improvement in ADHD scores in adults, and that associated phase advances were the most significant predictor of clinical improvements. The chronobiotic antidepressant agomelatine, which is a melatoninergic agonist, may have promise as a second-line treatment for ADHD (Niederhofer, 2012). Melatonin treatment in childhood ADHD patients suffering from insomnia has been shown to improve a number of sleep measures including an increase in the mean total time asleep and sleep efficiency, and a decrease in sleep latency, nocturnal restlessness and difficulty falling asleep (Van der Heijden et al., 2005). Furthermore, sleep onset and dim light melatonin onset was advanced to that of values found in healthy children not suffering from insomnia, and this effect was more pronounced in individuals who exhibited more extreme delays in dim light melatonin onset at baseline (Van der Heijden et al., 2005). However, whilst these sleep deficits were improved, no improvement of behaviour, cognitive function or quality of life was observed in these individuals, indicating that longer treatment duration would be required. The use of blue light-blocking sunglasses, which filter out light wavelengths that impact the most on the circadian system, to block the phase-delaying effects of evening light has been shown to reduce sleep-disturbances in ADHD patients (Fargason et al., 2013c). The phase-advancing impact of morning bright light has been postulated to contribute to the epidemiological observation that geographical areas with higher sunlight levels also have lower levels of ADHD prevalence, and that this association is independent of vitamin D levels (Arns et al., 2013). Indeed, such effects of light have been postulated to explain the association between altitude and regional variations in ADHD prevalence in children (Huber et al., 2015) due to the relationship between altitude and solar intensity (Arns et al., 2015).

\subsection{Mechanisms linking the circadian system to ADHD}

Given that ADHD is a highly heritable condition (Hawi et al., 2015), there may be genetic links between the disorder and the circadian system that provide mechanistic links to explain the occurrence of circadian dysfunction in ADHD. Genome-wide association studies have implicated circadian clock gene polymorphisms with ADHD: Lasky-Su et al. (2008) identified PER1 as being associated with ADHD in 
childhood and adolescence, whilst Brookes et al. (2006) report a speculative association of ADHD with polymorphisms in PER2. The association of the T-allele of the rs1801260 SNP in CLOCK with adult ADHD symptoms has been described by a number of groups (Kissling et al., 2008; Xu et al., 2010; Jeong et al., 2014). This polymorphism has also been shown to be associated with evening preference and delayed sleep timing (Katzenberg et al., 1998, Mishima et al., 2005), although this is not an undisputed finding (Pedrazzoli et al., 2007; Robillard et al., 2002). Further, the functional consequence of the relevant singlenucleotide polymorphism on CLOCK expression or function is not known. However, given that the rs1801260 polymorphism is present in the $3^{\prime}$ untranslated region of CLOCK it is possible that on a molecular level this SNP could impact upon mRNA stability and translation and polyadenylation signalling (Xu et al., 2010).Animal models of clock gene knockouts demonstrate that some of these show ADHD-like phenotypes. Zebrafish per1b and mouse per1 knockouts display hyperactivity and impulsive-like and attention-deficit-like behaviours (Huang et al., 2015). Further, the circadian system is known to be an important regulator of the dopaminergic system, which in turn is of central importance in current aetiological understanding of ADHD (Parekh et al., 2015). Indeed, altered clock function in dopaminergic neurons has been linked to bipolar mania-like symptoms (Sidor et al., 2015). Therefore there may be a fundamental link through which circadian dysfunction alters dopaminergic function and contributes to ADHD aetiology and symptoms. This is an area that warrants considerable and careful future attention.

Progress in delineating mechanistic links between molecular clocks and ADHD aetiology will depend on the use of appropriate animal models of ADHD. The use of such animal models must be driven by careful assessment of the validity of such models. The spontaneous hypertensive rat (SHR) is a well documented rodent model for ADHD that appears to have reasonable face, construct and predictive validity (Russell, 2007). A number of anomalies in the dopaminergic and noradrenergic systems have been observed in SHRs, including reduced dopamine transporter (DAT) expression in the prenatal SHR midbrain and elevated DAT expression in the adult SHR (Watanabe et al., 1997, Leo et al., 2003, Russell, 2007). Interestingly SHRs also exhibit abnormal circadian rhythms. The expression of vip mRNA, encoding a key circadian neuropeptide, has been shown to be elevated in the SHR brain (Peters et al., 1994). Moreover, significant alterations in the circadian rhythm of locomotor activity of SHR are present, including phase advances in wheel running behaviour under light-dark cycles, as well as shortened circadian period in free-running conditions in constant light or constant darkness (Peters et al., 1994). Additionally, SHRs differ in their responses to phase advances and delays of the light-dark cycle, with SHRs taking significantly longer to entrain to a phase delay, whilst being significantly quicker to entrain to a phase advance compared to controls (Peters et al., 1994). SHRs have also been found to differ from the Wistar-Kyoto rat control model (WKY) in its light sensitivity (Rosenwasser, 1993; Rosenwasser and Plante, 1993), and sleep alterations in the SHR model in comparison to WKY have been observed, including more frequent interruptions to sleep being found in SHRs (Kuo et al., 2004). It seems likely that further important mechanistic insight into linking ADHD-symptoms and circadian rhythms can be gleaned through further carefully designed animal experiments, and that such an approach may have a powerful effect on informing future clinical work on this problem. For example, Kooij and Bijlenga (2014) have recently postulated that the higher than expected prevalence of photophobia in ADHD may reflect a deficit in non-visual photictransmission associated with the circadian system, and that such a change could lead to the phase alterations observed in ADHD. This is a hypothesis that could be usefully tested in animal models of both ADHD and altered non-visual photoreceptor function.

Another important factor to consider is the extent to which stimulant and non-stimulant medications used in the management of ADHD may impact on circadian rhythms (Fig. 1). A number of studies in animal models have shown that the psychostimulant methylphenidate can impact on behavioural diurnal and circadian rhythms (Algahim et al., 2009; Antle et al., 2012), as well as impacting on SCN neurophysiology (Antle et al., 2012) and diurnal patterns of clock gene expression in

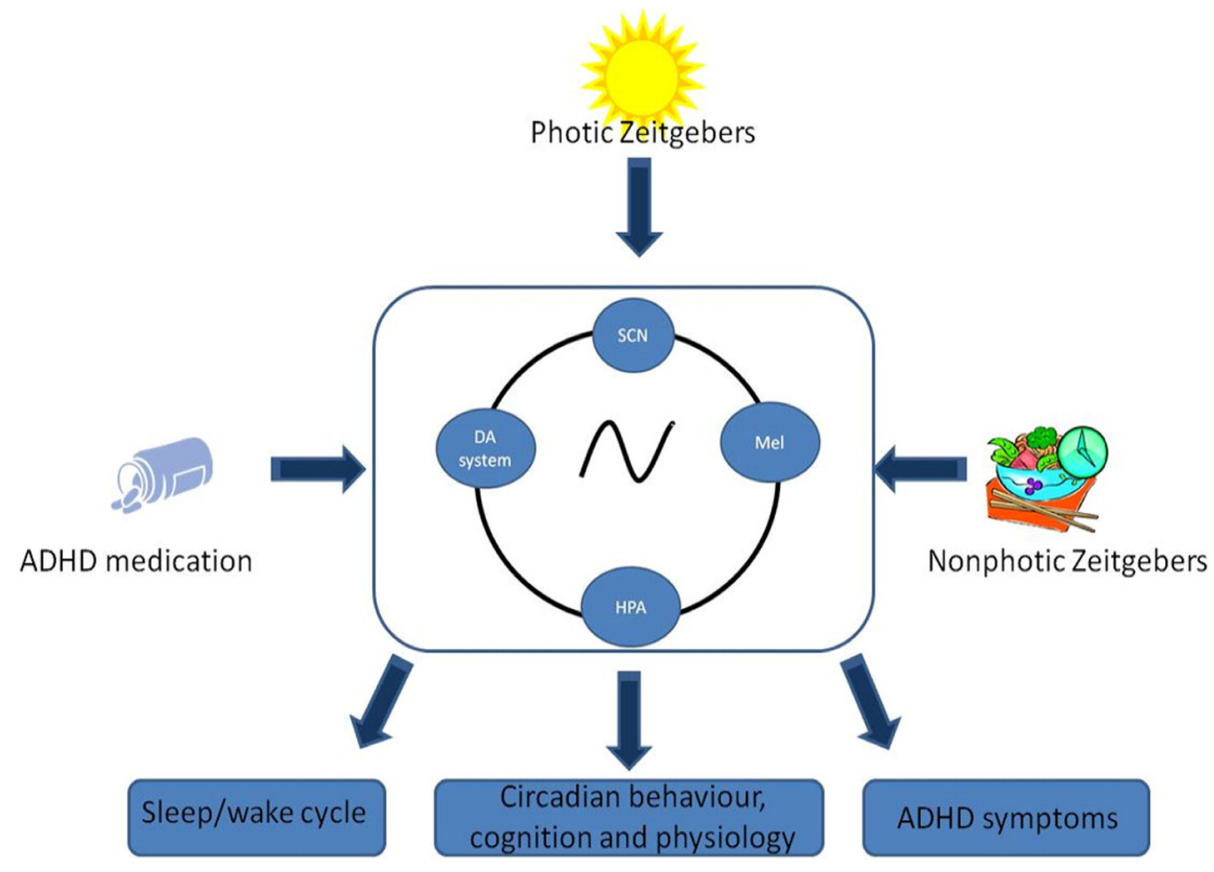

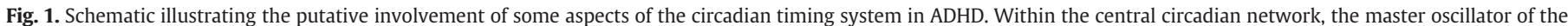

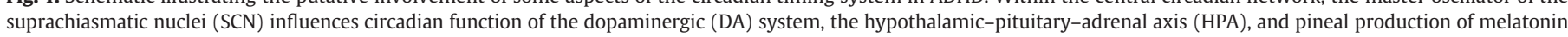

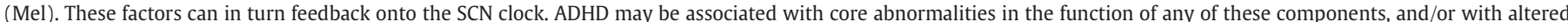

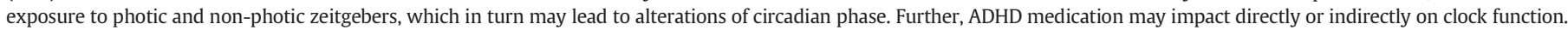

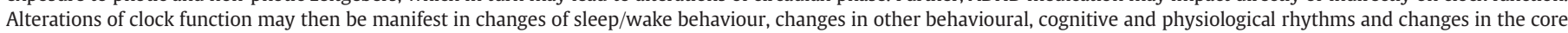
domains of ADHD, namely inattention, impulsivity and hyperactivity. 
the SCN and other areas (Baird et al., 2013). Further, the non-stimulant atomoxetine can alter circadian rhythms and clock gene expression also (O'Keeffe et al., 2012; Baird et al., 2013). Methylphenidate use has been shown to adversely affect some sleep parameters (such as sleep latency and sleep duration), but to benefit other parameters such as sleep efficiency (Boonstra et al., 2007; Coogan et al., 2015). Therefore in studies of circadian rhythmicity in ADHD it is important to consider the implications of ADHD medication on the parameters examined. As such future studies should include both medicated and non-medicated ADHD cohorts, where possible.

\subsection{Conclusion and agenda for future research}

Similar to other neuropsychiatric and neurological disorders (Wulff et al., 2010), circadian timekeeping appears to be altered in ADHD. One interesting facet of such alterations in ADHD is the relatively strong concordance between different studies indicating phase delays associated with ADHD (certainly in the adult form of the condition) as assessed by endocrine, molecular, activity, sleep and psychometric parameters. This appears to be in contrast with the situation in some other important disorders, such as major depression, seasonal affective disorder or bipolar disorder wherein there is a mixture of reports of phase advances or phase delays of rhythms (Landgraf et al., 2014), and in neurodegenerative conditions such as Alzheimer's disease in which the key circadian characteristic appears to be dampened amplitude rather than alterations in phase (Coogan et al., 2013). The significance of the observed phase alterations and desynchronisation of rhythms observed in ADHD is not fully understood, but these may provide novel therapeutic targets.

There is some promising preliminary data that suggests that approaches targetting phase-misalignments may produce benefits in terms of ADHD symptom relief (Rybak et al., 2006; Niederhofer, 2012). However, considerably more effort is needed in this area. There is a clear need for larger scale trials of chronotherapy in ADHD populations. Such therapy may take the form of environmental manipulations, such a light therapy, behavioural approaches shown to alter circadian phase such as total sleep deprivation (Bunney et al., 2015), or pharmacotherapeutic approaches involving administration of chronobiotics such as melatonin or the tailoring of timing of existing stimulant and non-stimulant treatments to achieve better clinical outcomes. Understanding circadian rhythm changes at the level of individual patients may be important in designing interventions that have maximal efficacy, and so hand-in-hand with chronotherapy there should be chronodiagnostic approaches to understand the particular circadian rhythm abnormality to be addressed in any given patient. Such an approach could lead to exciting developments in the management of ADHD that could benefit millions of patients.

\section{References}

Abrahamson, E.E., Moore, R.Y., 2001. Suprachiasmatic nucleus in the mouse: retinal innervation, intrinsic organization and efferent projections. Brain Res. 916, 172-191.

Albrecht, U., 2012. Timing to perfection: the biology of central and peripheral circadian clocks. Neuron 74, 246-260.

Algahim, M.F., Yang, P.B., WilcoxVT, B.K.D., Swann, A.C., Dafny, N., 2009. Prolonged methylphenidate treatment alters the behavioral diurnal activity pattern of adult male Sprague-Dawley rats. Pharmacol. Biochem. Behav. 92, 93-99.

Amons, P.J., Kooij, J.J., Haffmans, P.M., Hoffman TO, Hoencamp, E., 2006. Seasonality of mood disorders in adults with lifetime attention-deficit/hyperactivity disorder (ADHD). J. Affect. Disord. 91, 251-255.

Antle, M.C., Mistlberger, R.E., 2000. Circadian clock resetting by sleep deprivation without exercise in the Syrian hamster. J. Neurosci. 20, 9326-9332.

Antle, M.C., van Diepen, H.C., Deboer, T., Pedram, P., Pereira, R.R., Meijer, J.H., 2012. Methylphenidate modifies the motion of the circadian clock. Neuropsychopharmacology 37, 2446-2455

Arendt, J., 2005a. Melatonin in humans: it's about time. J. Neuroendocrinol. 17, 537-538

Arendt, J., 2005b. Melatonin: characteristics, concerns, and prospects. J. Biol. Rhythm. 20 291-303.
Arns, M., van der Heijden, K.B., Arnold, L.E., Kenemans, J.L., 2013. Geographic variation in the prevalence of attention-deficit/hyperactivity disorder: the sunny perspective. Biol. Psychiatry 74, 585-590.

Arns, M., Swanson, J.M., Arnold, L.E., 2015. ADHD prevalence: altitude or sunlight? Better understanding the interrelations of dopamine and the circadian system. J. Atten. Disord. (2015 Sep 4 E-pub).

Babkoff, H., Caspy, T., Mikulincer, M., 1991. Subjective sleepiness ratings: the effects of sleep deprivation, circadian rhythmicity and cognitive performance. Sleep 14, 534-539.

Baird, A.L., Coogan, A.N., Siddiqui, A., Donev, R.M., Thome, J., 2012. Adult attention-deficit hyperactivity disorder is associated with alterations in circadian rhythms at the behavioural, endocrine and molecular levels. Mol. Psychiatry 17, 988-995.

Baird, A.L., Coogan, A.N., Kaufling, J., Barrot, M., Thome, J., 2013. Daily methylphenidate and atomoxetine treatment impacts on clock gene protein expression in the mouse brain. Brain Res. 1513, 61-71.

Belle, M.D., Diekman, C.O., Forger, D.B., Piggins, H.D., 2009. Daily electrical silencing in the mammalian circadian clock. Science 326, 281-284.

Biederman, J., Faraone, S.V., 2005. Attention-deficit hyperactivity disorder. Lancet 366, 237-248.

Bijlenga, D., van der Heijden, K.B., Breuk, M., van Someren, E.J., Lie, M.E., Boonstra, A.M., Swaab, H.J., Kooij, J.J., 2013a. Associations between sleep characteristics, seasonal depressive symptoms, lifestyle, and ADHD symptoms in adults. J. Atten. Disord. 17, 261-275.

Bijlenga, D., Van Someren, E.J., Gruber, R., Bron, T.I., Kruithof, I.F., Spanbroek, E.C., Kooij, J.J., 2013b. Body temperature, activity and melatonin profiles in adults with attentiondeficit/hyperactivity disorder and delayed sleep: a case-control study. J. Sleep Res. 22, 607-616

Blomqvist, M., Holmberg, K., Lindblad, F., Fernell, E., Ek, U., Dahllöf, G., 2007. Salivary cortisol levels and dental anxiety in children with attention deficit hyperactivity disorder. Eur. J. Oral Sci. 115, 1-6.

Boonstra, A.M., Kooij, J.J., Oosterlaan, J., Sergeant, J.A., Buitelaar, J.K., Van Someren, E.J., 2007. Hyperactive night and day? Actigraphy studies in adult ADHD: a baseline comparison and the effect of methylphenidate. Sleep 30, 433-442.

Borbély, A.A., 1982. A two process model of sleep regulation. Hum. Neurobiol. 1, 195-204.

Breslau, N., Roth, T., Rosenthal, L., Andreski, P., 1996. Sleep disturbance and psychiatric disorders: a longitudinal epidemiological study of young adults. Biol. Psychiatry 39, 411-418.

Brookes, K., X, X., Chen, W., Zhou, K., Neale, B., Lowe, N., Anney, R., Franke, B., Gill, M., Ebstein, R., Buitelaar, J., Sham, P., Campbell, D., Knight, J., Andreou, P., Altink, M. Arnold, R., Boer, F., Buschgens, C., Butler, L., Christiansen, H., Feldman, L., Fleischman, K., Fliers, E., Howe-Forbes, R., Goldfarb, A., Heise, A., Gabriëls, I., KornLubetzki, I., Johansson, L., Marco, R., Medad, S., Minderaa, R., Mulas, F., Müller, U., Mulligan, A., Rabin, K., Rommelse, N., Sethna, V., Sorohan, J., Uebel, H., Psychogiou, L., Weeks, A., Barrett, R., Craig, I., Banaschewski, T., Sonuga-Barke, E., Eisenberg, J., Kuntsi, J., Manor, I., McGuffin, P., Miranda, A., RD, O., Plomin, R., Roeyers, H., Rothenberger, A., Sergeant, J., HC, S., Taylor, E., Thompson, M., SV, F., Asherson, P., 2006. The analysis of 51 genes in DSM-IV combined type attention deficit hyperactivity disorder: association signals in DRD4, DAT1 and 16 other genes. Mol. Psychiatry $11,53-934$

Bunney, B.G., Li, J.Z., Walsh, D.M., Stein, R., Vawter, M.P., Cartagena, P., Barchas, J.D., Schatzberg, A.F., Myers, R.M., Watson, S.J., Akil, H., Bunney, W.E., 2015. Circadian dysregulation of clock genes: clues to rapid treatments in major depressive disorder. Mol. Psychiatry 20, 48-55.

Buttgereit, F., Smolen, J.S., Coogan, A.N., Cajochen, C., 2015. Clocking in: chronobiology in rheumatoid arthritis. Nat. Rev. Rheumatol.

Chervin, R.D., 2005. How many children with ADHD have sleep apnea or periodic leg movements on polysomnography? Sleep 28, 1041-1042.

Chervin, R.D., Ruzicka, D.L., Archbold, K.H., Dillon, J.E., 2005. Snoring predicts hyperactivity four years later. Sleep 28, 885-890.

Chiang, H.L., Gau, S.S., Ni, H.C., Chiu, Y.N., Shang, C.Y., Wu, Y.Y., Lin, L.Y., Tai, Y.M., Soong, W.T., 2010. Association between symptoms and subtypes of attentiondeficit hyperactivity disorder and sleep problems/disorders. J. Sleep Res. 19, $535-545$.

Coogan, A.N., Schutová, B., Husung, S., Furczyk, K., Baune, B.T., Kropp, P., Häßler, F., Thome, J., 2013. The circadian system in Alzheimer's disease: disturbances, mechanisms, and opportunities. Biol. Psychiatry 74, 333-339.

Coogan, A.N., Baird, A.L., Thome, J., 2015. Impact of methylphenidate on clock gene expression and circadian rhythms. In: Preedy, V. (Ed.), Neuropathology of Drug Addiction. Academic Press (in press).

Corkum, P., Tannock, R., Moldofsky, H., 1998. Sleep disturbances in children with attention-deficit/hyperactivity disorder. J. Am. Acad. Child Adolesc. Psychiatry 37, 637-646.

Deboer, T., Détári, L., Meijer, J.H., 2007. Long term effects of sleep deprivation on the mammalian circadian pacemaker. Sleep 30, 257-262.

Dagan, Y., Zeevi-Luria, S., Sever, Y., Hallis, D., Yovel, I., Sadeh, A., Dolev, E., 1997. Sleep quality in children with attention deficit hyperactivity disorder: an actigraphic study. Psychiatry Clin. Neurosci. 51, 383-386.

Dane, A.V., Schachar, R.J., Tannock, R., 2000. Does actigraphy differentiate ADHD subtypes in a clinical research setting? J. Am. Acad. Child Adolesc. Psychiatry 39, 752-760.

Dibner, C., Schibler, U., Albrecht, U., 2010. The mammalian circadian timing system: organization and coordination of central and peripheral clocks. Annu. Rev. Physiol. 72, 517-549.

Diekelmann, S., Born, J., 2010. The memory function of sleep. Nat. Rev. Neurosci. 11, 114-126. 
Fargason, R.E., Hollar, A.F., White, S., Gamble, K.L., 2013a. Adults with ADHD-without insomnia history have subclinical sleep disturbance but not circadian delay: an ADHD phenotype? J. Atten. Disord. 17, 583-588.

Fargason, R.E., White, B.A., Gamble, K.L., 2013b. Complete sleep-wake cycle reversal related to ADHD detected by actigraphy. Ann. Clin. Psychiatry 25 (3), E8-E9.

Fargason, R.E., Preston, T., Hammond, E., May, R., Gamble, K.L., 2013c. Treatment of attention deficit hyperactivity disorder insomnia with blue wavelength light-blocking glasses. Chronophysiol Ther. 3, 1-8.

Franken, P., 2013. A role for clock genes in sleep homeostasis. Curr. Opin. Neurobiol. 23, 864-872.

Freitag, C.M., Hänig, S., Palmason, H., Meyer, J., Wüst, S., Seitz, C., 2009. Cortisol awakening response in healthy children and children with ADHD: impact of comorbid disorders and psychosocial risk factors. Psychoneuroendocrinology 34, 1019-1028.

Freyburger, M., Pierre, A., Paquette, G., Bélanger-Nelson, E., Bedont, J., Gaudreault, P.O. Drolet, G., Laforest, S., Blackshaw, S., Cermakian, N., Doucet, G., Mongrain, V., 2015. EphA4 is involved in sleep regulation but not in the electrophysiological response to sleep deprivation. Sleep E-pub. Nov 192015

Gamble, K.L., May, R.S., Besing, R.C., Tankersly, A.P., Fargason, R.E., 2013. Delayed sleep timing and symptoms in adults with attention-deficit/hyperactivity disorder: a controlled actigraphy study. Chronobiol. Int. 30, 598-606.

Gau, S.S., Kessler, R.C., Tseng, W.L., Wu, Y.Y., Chiu, Y.N., Yeh, C.B., Hwu, H.G., 2007. Association between sleep problems and symptoms of attention-deficit/hyperactivity disorder in young adults. Sleep 30, 195-201.

Gruber, R., Sadeh, A., Raviv, A., 2000. Instability of sleep patterns in children with attention-deficit/hyperactivity disorder. J. Am. Acad. Child Adolesc. Psychiatry 39, 495-501.

Guilding, C., Piggins, H.D., 2007. Challenging the omnipotence of the suprachiasmatic timekeeper: are circadian oscillators present throughout the mammalian brain? Eur. J. NeuroSci. 25, 3195-3216.

Hastings, P.D., Fortier, I., Utendale, W.T., Simard, L.R., Robaey, P., 2009. Adrenocortical functioning in boys with attention-deficit/hyperactivity disorder: examining subtypes of ADHD and associated comorbid conditions. J. Abnorm. Child Psychol. 37, 565-578.

Hawi, Z., Cummins, T.D., Tong, J., Johnson, B., Lau, R., Samarrai, W., Bellgrove, M.A., 2015. The molecular genetic architecture of attention deficit hyperactivity disorder. Mol. Psychiatry 20, 289-297.

Hirvikoski, T., Lindholm, T., Nordenström, A., Nordström, A.L., Lajic, S., 2009. High selfperceived stress and many stressors, but normal diurnal cortisol rhythm, in adults with ADHD (attention-deficit/hyperactivity disorder). Horm. Behav. 55, 418-424.

Hong, H.J., Shin, D.W., Lee, E.H., Oh, Y.H., Noh, K.S., 2003. Hypothalamic-pituitary-adrenal reactivity in boys with attention deficit hyperactivity disorder. Yonsei Med. J. 44, 608-614.

Huang, J., Zhong, Z., Wang, M., Chen, X., Tan, Y., Zhang, S., He, W., He, X., Huang, G., Lu, H., Wu, P., Che, Y., Yan, Y.L., Postlethwait, J.H., Chen, W., Wang, H., 2015. Circadian modulation of dopamine levels and dopaminergic neuron development contributes to attention deficiency and hyperactive behavior. J. Neurosci. 35, 2572-2587.

Huber, R.S., Kim, T.S., Kim, N.J., Kuykendall, M.D., Sherwood, S.N., Renshaw, P.F., Kondo, D.G., 2015. Association between altitude and regional variation of ADHD in youth. Atten. Disord. (Epub Mar 25).

Hughes, S., Jagannath, A., Hankins, M.W., Foster, R.G., Peirson, S.N., 2015. Photic regulation of clock systems. Methods Enzymol. 552, 125-143.

Hysing, M., Lundervold, A.J., Posserud, M.-J., Sivertsen, B., 2015. Assocation between sleep problems and symptoms of attention deficit hyperactivity disorder in adolescence: results from a large population-based study. Behav. Sleep Med. E-Pub Oct 2015.

Jeong, S.H., Yu, J.C., Lee, C.H., Choi, K.S., Choi, J.E., Kim, S.H., Joo, E.J., 2014. Human CLOCK gene-associated attention deficit hyperactivity disorder-related features in healthy adults: quantitative association study using Wender Utah Rating Scale. Eur. Arch. Psychiatry Clin. Neurosci. 264, 71-81.

Jones, J.R., Tackenberg, M.C., McMahon, D.G., 2015. Manipulating circadian clock neuron firing rate resets molecular circadian rhythms and behavior. Nat. Neurosci. 18, 373-375.

Kaneko, M., Hoshino, Y., Hashimoto, S., Okano, T., Kumashiro, H., 1993. Hypothalamic-pituitary-adrenal axis function in children with attention-deficit hyperactivity disorder. J. Autism Dev. Disord. 23, 59-65.

Kang, J.I., Park, C.I., Sohn, S.Y., Kim, H.W., Namkoong, K., Kim, S.J., 2015. Circadian preference and trait impulsivity, sensation-seeking and response inhibition in healthy young adults. Chronobiol. Int. 32, 235-241.

Katzenberg, D., Young, T., Finn, L., Lin, L., King, D.P., Takahashi, J.S., Mignot, E., 1998. A CLOCK polymorphism associated with human diurnal preference. Sleep 21, 569-576.

Keller, J., Flores, B., Gomez, R.G., Solvason, H.B., Kenna, H., Williams, G.H., Schatzberg, A.F., 2006. Cortisol circadian rhythm alterations in psychotic major depression. Biol. Psychiatry 60, 275-281.

Kissling, C., Retz, W., Wiemann, S., Coogan, A.N., Clement, R.M., Hünnerkopf, R., Conner, A.C., Freitag, C.M., Rösler, M., Thome, J., 2008. A polymorphism at the $3^{\prime}$-untranslated region of the CLOCK gene is associated with adult attention-deficit hyperactivity disorder. Am. J. Med. Genet. B Neuropsychiatr. Genet. 147, 333-338.

Koike, N., Yoo, S.H., Huang, H.C., Kumar, V., Lee, C., Kim, T.K., Takahashi, J.S., 2012. Transcriptional architecture and chromatin landscape of the core circadian clock in mammals. Science 338, 349-354.

Kooij, J.J., Bijlenga, D., 2013. The circadian rhythm in adult attention-deficit/hyperactivity disorder: current state of affairs. Expert. Rev. Neurother. 13, 1107-1116.

Kuo, T.B., Shaw, F.Z., Lai, C.J., Lai, C.W., Yang, C.C., 2004. Changes in sleep patterns in spontaneously hypertensive rats. Sleep 27, 406-412.

Lack, L.C., Gradisar, M., Van Someren, E.J., Wright, H.R., Lushington, K., 2008. The relationship between insomnia and body temperatures. Sleep Med. Rev. 12, 307-317.
Lackschewitz, H., Hüther, G., Kröner-Herwig, B., 2008. Physiological and psychologica stress responses in adults with attention-deficit/hyperactivity disorder (ADHD). Psychoneuroendocrinology 33, 612-624.

Lall, G.S., Atkinson, L.A., Corlett, S.A., Broadbridge, P.J., Bonsall, D.R., 2012. Circadian entrainment and its role in depression: a mechanistic review. J. Neural Transm. 119, 1085-1096.

Landgraf, D., McCarthy, M.J., Welsh, D.K., 2014. The role of the circadian clock in animal models of mood disorders. Behav. Neurosci. 128, 344-359.

Lasky-Su, J., Neale, B.M., Franke, B., Anney, R.J., Zhou, K., Maller, J.B., Vasquez, A.A., Chen, W., Asherson, P., Buitelaar, J., Banaschewski, T., Ebstein, R., Gill, M., Miranda, A., Mulas, F., Oades, R.D., Roeyers, H., Rothenberger, A., Sergeant, J., Sonuga-Barke, E. Steinhausen, H.C. Taylor, E., Daly, M., Laird, N., Lange, C., Faraone, S.V., 2008. Genome-wide association scan of quantitative traits for attention deficit hyperactivity disorder identifies novel associations and confirms candidate gene associations. Am. J. Med. Genet. B Neuropsychiatr. Genet. 147B, 1345-1354.

Lee, M.L., Swanson, B.E., de la Iglesia, H.O., 2009. Circadian timing of REM sleep is coupled to an oscillator within the dorsomedial suprachiasmatic nucleus. Curr. Biol. 19, 848-852.

Leo, D., Sorrentino, E., Volpicelli, F., Eyman, M., Greco, D., Viggiano, D., di Porzio, U. Perrone-Capano, C., 2003. Altered midbrain dopaminergic neurotransmission during development in an animal model of ADHD. Neurosci. Biobehav. Rev. 27, 661-669.

Levitan, R.D., Jain, U.R., Katzman, M.A., 1999. Seasonal affective symptoms in adults with residual attention-deficit hyperactivity disorder. Compr. Psychiatry 40, 261-267.

Lewy, A.J., Lefler, B.J., Emens, J.S., Bauer, V.K., 2006. The circadian basis of winter depression. Proc. Natl. Acad. Sci. U. S. A. 103, 7414-7419.

Lim, C.G., Ooi, Y.P., Fung, D.S., Mahendran, R., Kaur, A., 2008. Sleep disturbances in Singaporean children with attention deficit hyperactivity disorder. Ann. Acad. Med. Singap. 37, 655-661.

Littner, M., Kushida, C.A., Anderson, W.M., Bailey, D., Berry, R.B., Davila, D.G. Hirshkowitz M., Kapen, S., Kramer, M., Loube, D., Wise, M., Johnson, S.F., Medicine, S., 2003. Practice parameters for the role of actigraphy in the study of sleep and circadian rhythms: an update for 2002. Sleep 26, 337-341.

Mahajan, N., Hong, N., Wigal, T.L., Gehricke, J.G., 2010. Hyperactive-impulsive symptoms associated with self-reported sleep quality in nonmedicated adults with ADHD J. Atten. Disord. 14, 132-137.

McArthur, A.J., Coogan, A.N., Ajpru, S., Sugden, D., Biello, S.M., Piggins, H.D., 2000. Gastrinreleasing peptide phase-shifts suprachiasmatic nuclei neuronal rhythms in vitro. J Neurosci 20, 5496-5502.

Meng, Q.J., Logunova, L., Maywood, E.S., Gallego, M., Lebiecki, J., Brown, T.M., Sládek, M. Semikhodskii, A.S., Glossop, N.R., Piggins, H.D., Chesham, J.E., Bechtold, D.A., Yoo, S.H., Takahashi, J.S., Virshup, D.M., Boot-Handford, R.P., Hastings, M.H., Loudon, A.S. 2008. Setting clock speed in mammals: the CK1 epsilon tau mutation in mice accelerates circadian pacemakers by selectively destabilizing PERIOD proteins. Neuron 58, 78-88.

Mishima, K., Tozawa, T., Satoh, K., Saitoh, H., Mishima, Y., 2005. The 3111T/C polymorphism of hClock is associated with evening preference and delayed sleep timing in a Japanese population sample. Am. J. Med. Genet. B Neuropsychiatr. Genet. 133B, 101-104.

Moss, H.B., Vanyukov, M.M., Martin, C.S., 1995. Salivary cortisol responses and the risk for substance abuse in prepubertal boys. Biol. Psychiatry 38, 547-555.

Neubauer, D.N., 2015. Tasimelteon for the treatment of non-24-hour sleep-wake disorder. Drugs Today (Barc) 51, 29-35.

Nicolaides, N.C., Charmandari, E., Chrousos, G.P., Kino, T., 2014. Circadian endocrine rhythms: the hypothalamic-pituitary-adrenal axis and its actions. Ann. N. Y. Acad. Sci. 1318, 71-80.

Niederhofer, H., 2012. Treating ADHD with agomelatine. J. Atten. Disord. 16, 346-348.

Nováková, M., Paclt, I., Ptáček, R., Kuželová, H., Hájek, I., Sumová, A., 2011. Salivary melatonin rhythm as a marker of the circadian system in healthy children and those with attention-deficit/hyperactivity disorder. Chronobiol. Int. 28, 630-637.

O'Brien, L.M., Ivanenko, A., Crabtree, V.M., Holbrook, C.R., Bruner, J.L., Klaus, C.J., Gozal, D 2003a. Sleep disturbances in children with attention deficit hyperactivity disorder. Pediatr. Res. 54, 237-243.

O'Brien, L.M., Ivanenko, A., Crabtree, V.M., Holbrook, C.R., Bruner, J.L., Klaus, C.J., Gozal, D. 2003b. The effect of stimulants on sleep characteristics in children with attention deficit/hyperactivity disorder. Sleep Med. 4, 309-316.

O'Keeffe, S.M., Thome, J., Coogan, A.N., 2012. The noradrenaline reuptake inhibitor atomoxetine phase-shifts the circadian clock in mice. Neuroscience 201, 219-230.

Ottoni, G.L., Antoniolli, E., Lara, D.R., 2012. Circadian preference is associated with emotional and affective temperaments. Chronobiol. Int. 29, 786-793.

Parekh, P.K., Ozburn, A.R., McClung, C.A., 2015. Circadian clock genes: effects on dopamine, reward and addiction. Alcohol 49, 341-349.

Pedrazzoli, M., Louzada, F.M., Pereira, D.S., Benedito-Silva, A.A., Lopez, A.R., Martynhak, B.J., Korczak, A.L., Koike, B.E.V., Barbosa, A.A., D'Almeida, V., Tufik, S., 2007. Clock polymorphisms and circadian rhythms phenotypes in a sample of the Brazilian population. Chronobiol. Int. 24, 1-8.

Peters, R.V., Zoeller, R.T., Hennessey, A.C., Stopa, E.G., Anderson, G., Albers, H.E., 1994. The control of circadian rhythms and the levels of vasoactive intestinal peptide mRNA in the suprachiasmatic nucleus are altered in spontaneously hypertensive rats. Brain Res. 639, 217-227.

Pevet, P., Challet, E., 2011. Melatonin: both master clock output and internal time-giver in the circadian clocks network. J. Physiol. Paris 105, 170-182.

Picchietti, D.L., England, S.J., Walters, A.S., Willis, K., Verrico, T., 1998. Periodic limb movement disorder and restless legs syndrome in children with attention-deficit hyperactivity disorder. J. Child Neurol. 13, 588-594. 
Pritchett, D., Wulff, K., Oliver, P.L., Bannerman, D.M., Davies, K.E., Harrison, P.J., Peirson, S.N., Foster, R.G., 2012. Evaluating the links between schizophrenia and sleep and circadian rhythm disruption. J. Neural. Transm. 119, 1061-1075.

Randazzo, W.T., Dockray, S., Susman, E.J., 2008. The stress response in adolescents with inattentive type ADHD symptoms. Child Psychiatry Hum. Dev. 39, 27-38.

Robilliard, D.L., Archer, S.N., Arendt, J., Lockley, S.W., Hack, L.M., English, J., Leger, D., Smits, M.G., Williams, A., Skene, D.J., Von Schantz, M., 2002. The 3111 Clock gene polymorphism is not associated with sleep and circadian rhythmicity in phenotypically characterized human subjects. J. Sleep Res. 11, 305-312.

Rosenwasser, A.M., 1993. Circadian drinking rhythms in SHR and WKY rats: effects of increasing light intensity. Physiol. Behav. 53, 1035-1041.

Rosenwasser, A.M., Plante, L., 1993. Circadian activity rhythms in SHR and WKY rats: strain differences and effects of clonidine. Physiol. Behav. 53, 23-29.

Rösler, M., Retz, W., Retz-Junginger, P., Hengesch, G., Schneider, M., Supprian, T., Schwitzgebel, P., Pinhard, K., Dovi-Akue, N., Wender, P., Thome, J., 2004 Prevalence of attention deficit/hyperactivity disorder (ADHD) and comorbid disorders in young male prison inmates. Eur. Arch. Psychiatry Clin. Neurosci. $254,365-371$.

Russell, V.A., 2007. Neurobiology of animal models of attention-deficit hyperactivity disorder. J. Neurosci. Methods 161, 185-198.

Rybak, Y.E., McNeely, H.E., Mackenzie, B.E., Jain, U.R., Levitan, R.D., 2006. An open trial of light therapy in adult attention-deficit/hyperactivity disorder. J. Clin. Psychiatry 67, 1527-1535.

Rybak, Y.E., McNeely, H.E., Mackenzie, B.E., Jain, U.R., Levitan, R.D., 2007. Seasonality and circadian preference in adult attention-deficit/hyperactivity disorder: clinical and neuropsychological correlates. Compr. Psychiatry 48, 562-571.

Schneider, M., Retz, W., Coogan, A., Thome, J., Rösler, M., 2006. Anatomical and functional brain imaging in adult attention-deficit/hyperactivity disorder (ADHD)-a neurological view. Eur. Arch. Psychiatry Clin. Neurosci. 256 (Suppl. 1), i32-i41.

Schredl, M., Alm, B., Sobanski, E., 2007. Sleep quality in adult patients with attention deficit hyperactivity disorder (ADHD). Eur. Arch. Psychiatry Clin. Neurosci. 257 164-168.

Schwartz, W.J., Gross, R.A., Morton, M.T., 1987. The suprachiasmatic nuclei contain a tetrodotoxin-resistant circadian pacemaker. Proc. Natl. Acad. Sci. U. S. A. 84, $1694-1698$

Sidor, M.M., Spencer, S.M., Dzirasa, K, Parekh, P.K, Tye, K.M., Warden, M.R., Arey, R.N Enwright 3rd, J.F., Jacobsen, J.P., Kumar, S., Remillard, E.M., Caron, M.G., Deisseroth, K., McClung, C.A., 2015. Daytime spikes in dopaminergic activity drive rapid moodcycling in mice. Mol. Psychiatry E-pub 2015 Jan 6.

Sivertsen, B., Harvey, A.G., Pallesen, S., Hysing, M., 2015. Mental health problems in adolescents with delayed sleep phase: results from a large population-based study in Norway. J. Sleep Res. 24, 11-18.

Smolensky, M.H., Portaluppi, F., Manfredini, R., Hermida, R.C., Tiseo, R., Sackett-Lundeen, L.L., Haus, E.L., 2015. Diurnal and twenty-four hour patterning of human diseases: acute and chronic common and uncommon medical conditions. Sleep Med. Rev. 21 $12-22$.
Sobanski, E., Schredl, M., Kettler, N., Alm, B., 2008. Sleep in adults with attention deficit hyperactivity disorder (ADHD) before and during treatment with methylphenidate: a controlled polysomnographic study. Sleep 31, 375-381.

Sondeijker, F.E., Ferdinand, R.F., Oldehinkel, A.J., Veenstra, R., Tiemeier, H., Ormel, J., Verhulst, F.C., 2007. Disruptive behaviors and HPA-axis activity in young adolescent boys and girls from the general population. J. Psychiatr. Res. 41, 570-578.

Stewart, R., Besset, A., Bebbington, P., Brugha, T., Lindesay, J., Jenkins, R., Singleton, N., Meltzer, H., 2006. Insomnia comorbidity and impact and hypnotic use by age group in a national survey population aged 16 to 74 years. Sleep 29, 1391-1397.

Thomas, R., Sanders, S., Doust, J., Beller, E., Glasziou, P., 2015. Prevalence of attentiondeficit/hyperactivity disorder: a systematic review and meta-analysis. Pediatrics 135, e994-1001.

Van der Heijden, K.B., Smits, M.G., Van Someren, E.J., Gunning, W.B., 2005. Idiopathic chronic sleep onset insomnia in attention-deficit/hyperactivity disorder: a circadian rhythm sleep disorder. Chronobiol. Int. 22, 559-570.

Van Someren, E.J., Riemersma-Van Der Lek, R.F., 2007. Live to the rhythm, slave to the rhythm. Sleep Med. Rev. 11, 465-484.

Van Veen, M.M., Kooij, J.J., Boonstra, A.M., Gordijn, M.C., Van Someren, E.J., 2010. Delayed circadian rhythm in adults with attention-deficit/hyperactivity disorder and chronic sleep-onset insomnia. Biol. Psychiatry 67, 1091-1096.

van West, D., Claes, S., Deboutte, D., 2009. Differences in hypothalamic-pituitary-adrenal axis functioning among children with ADHD predominantly inattentive and combined types. Eur. Child Adolesc. Psychiatry 18, 543-553.

Virkkunen, M., 1985. Urinary free cortisol secretion in habitually violent offenders. Acta Psychiatr. Scand. 72, 40-44.

Voinescu, B.I., Szentagotai, A., David, D., 2012. Sleep disturbance, circadian preference and symptoms of adult attention deficit hyperactivity disorder (ADHD). J. Neural Transm. 119, 1195-1204.

Walters, A.S., Silvestri, R., Zucconi, M., Chandrashekariah, R., Konofal, E., 2008. Review of the possible relationship and hypothetical links between attention deficit hyperactivity disorder (ADHD) and the simple sleep related movement disorders, parasomnias, hypersomnias, and circadian rhythm disorders. J. Clin. Sleep Med. 4, 591-600.

Watanabe, Y., Fujita, M., Ito, Y., Okada, T., Kusuoka, H., Nishimura, T., 1997. Brain dopamine transporter in spontaneously hypertensive rats. J. Nucl. Med. 38, 470-474.

Wulff, K., Gatti, S., Wettstein, J.G., Foster, R.G., 2010. Sleep and circadian rhythm disruption in psychiatric and neurodegenerative disease. Nat. Rev. Neurosci. 11, 589-599.

Xu, X., Breen, G., Chen, C.K., Huang, Y.S., Wu, Y.Y., Asherson, P., 2010. Association study between a polymorphism at the $3^{\prime}$-untranslated region of CLOCK gene and attention deficit hyperactivity disorder. Behav. Brain Funct. 6, 48.

Zhang, R., Lahens, N.F., Ballance, H.I., Hughes, M.E., Hogenesch, J.B., 2014. A circadian gene expression atlas in mammals: implications for biology and medicine. Proc. Natl. Acad. Sci. U. S. A. 111, 16219-16224. 